\title{
Volunteering with Newcomers: The Perspectives of Canadian- and Foreign-born Volunteers
}

\author{
Behnam Behnia
}

Carleton University

\begin{abstract}
Canadian- and foreign-born volunteers have contributed to the settlement of newcomers into Canadian society. Despite their important contribution, little has been reported about the experiences and perspectives of these volunteers. Using the information collected from face-to-face interviews with 60 Canadian- and foreign-born volunteers who support newcomers, this article discusses factors that motivate people to volunteer with newcomers. The study results revealed among other findings that (1) to become a volunteer, one not only needs to be motivated but also needs to believe that volunteering will produce the expected positive results and to have confidence in one's ability to complete the assigned tasks, (2) once people become volunteers, the experience of volunteering tests their perceived self-efficacy and their belief about the effectiveness of their volunteer work. Success or failure in their expectations influences their decision to continue or discontinue their volunteer work.

\section{RÉSUMÉ}

De nombreux bénévoles nés au Canada et à l'étranger contribuent à l'intégration de nouveaux venus dans la société canadienne. Malgré leurs contributions importantes, il y a peu d'écrits sur les expériences et perspectives de ces bénévoles. Cet article se fonde sur des entrevues face à face avec soixante bénévoles nés au Canada ou à l'étranger afin de mieux comprendre ce qui les motive à aider les nouveaux venus. Les résultats révèlent entre autres que (1) pour devenir bénévole, non seulement faut-il être motivé mais il faut aussi croire que le bénévolat entraînera bien les effets positifs escomptés et être confiant de son aptitude à accomplir les tâches assignées et (2) l'expérience du bénévolat met à l'épreuve la perception de sa propre efficacité et l'impression qu'on a de la valeur de son travail bénévole. Le succès ou l'échec de ces attentes a une influence sur la décision de continuer à faire du bénévolat ou non.
\end{abstract}

Keywords / Mots clés : Newcomers; Resettlement; Formal volunteering; Motivation / Nouveaux venus; Relocalisation; Bénévolat formel; Motivation 
Kindness of strangers during the need, you know, remains with you. And that's a motivating factor that you know later on when your time comes you will be in a position to give back because you

have the taste of it aside from what is the tradition of your family.

(Female refugee interview respondent)

\section{INTRODUCTION}

Researchers have identified a number of factors that negatively influence the successful integration of immigrants, in particular the newly arrived, into Canadian society (Basran \& Zong, 1998; Bauder, 2003; Creese \& Kambere, 2003; Reitz, 2005). Some of these obstacles (e.g., lack of recognition of credentials, Canadian work experience requirements, and discrimination) require interventions at structural, institutional, and policy levels. There are other obstacles (e.g., social isolation, lack of language proficiency, knowledge of cultural values, and access to information on employment opportunities) that can be ameliorated by the presence of strong and extended social support networks. It has been noted that newcomers to Canada often suffer from a shortage of adequate social support networks (Behnia, 2004; Beiser, 1999; Couton \& Gaudet, 2008; Lamba \& Harvey, 2003; Raj \& Silverman, 2002).

To address this challenge a number of organizations match newcomers with volunteers who act as friends and offer practical, informational, and emotional support for a determinate period of time (Behnia, 2007). These volunteers help newcomers in areas such as job search, resumé writing, learning about Canadian society and culture, improving language and communication skills, expanding their social networks, and enhancing their ability to access community resources and services (Behnia, 2004; Behnia \& Bergin, 2001; Canadian Centre for Victims of Torture, n.d.; Charbonneau \& Laaroussi, 2003; Citizenship and Immigration Canada, 2004; Lanphier \& Lukomskyj, 1994; Thompson, 1988; Yan \& Lauer, 2008). It is reported that compared to other immigrants and refugees, immigrants and refugees who are matched with volunteers obtain employment sooner, perform better in language acquisition, receive less government financial assistance, have more friends, and are more optimistic about their future (Citizenship and Immigration Canada, 2004; Employment and Immigration Canada, 1986; Lanphier, 1993).

Despite their important contribution to the settlement and integration of immigrants into Canadian society, little has been reported about individuals who volunteer with newcomers, especially in relation to the factors that influence their decision to join and remain with an organization, and their perspectives and experiences of volunteering. Using the results of a qualitative exploratory study on formal volunteering with newcomers in Ottawa (Canada), this article aims to fill in some of the gaps in this knowledge by examining the perspectives and experiences of Canadian- and foreign-born individuals who volunteer with newcomers.

\section{DETERMINANTS OF FORMAL VOLUNTEERING}

Distinct from informal volunteering, viewed as spontaneous and haphazard behaviour, formal volunteering is defined in this article as a non-spontaneous form of helping behaviour offered by individuals to others within the context of an organization in a coordinated way, without coercion, remuneration, or direct financial rewards (Clary \& Snyder, 1991; Dekker \& Halman, 2003; Kearney, 2001; Penner, 2002; Wilson, 2000). To become a formal volunteer, one must be able and motivated to dedicate personal resources such as time, energy, and skills to an established organization (Behnia \& Bergin, 2001).

Research on volunteers indicates that people do volunteer work to maintain or enhance the welfare and wellbeing of others (altruistic reasons) and of themselves (self-interest reasons) (Ashton, Baker, \& Parandeh, 
2006; Behnia \& Bergin, 2001; De Long, 2005; Fischer \& Schaffer, 1993; Fletcher \& Fast, 2009; Handy \& Greenspan, 2008; Stürmer \& Snyder, 2010; Vallee \& Caputo, 2010; Wymer, Riecken, \& Yavas, 1996). Further, people may volunteer because of a desire to help others, give something back to the community, meet people, feel useful, get distracted from the losses caused by migration, learn new skills, improve their language proficiency, gain Canadian work experiences, and improve their job opportunities.

Once a prospective volunteer feels ready to dedicate their resources to an organization, they usually screen various organizations and programs in order to select the desired one (Behnia \& Bergin, 2001). The prospective volunteer must have a positive perception of an organization and its clients and have a satisfactory experience in his/her initial contact with the organization (Behnia, 2007; Behnia \& Bergin, 2001; Gill \& Mawby, 1990; Snyder \& Omoto, 1992). Individuals are more willing to volunteer their time and skills to an organization if there is compatibility between their personal goals, values, ideologies, and those of the organization. It is also important that they feel connected to the organization's clients, and the organization's reputation (Behnia, 2007; Behnia \& Bergin, 2001; Fischer \& Schaffer, 1993; Gill \& Mawby, 1990; Pearce, 1993; Snyder, Omoto, \& Crain, 1999; Snyder \& Omoto, 1992; Wilson, 2000).

After becoming a volunteer, satisfaction with the tasks they are assigned, clients, and the way they are treated by the organization is crucial to the volunteer's commitment. Research shows that volunteers are more likely to remain committed to an organization when they are given meaningful tasks to do (Behnia, 2007; Behnia \& Bergin, 2001; Snyder \& Omoto, 1992; Wilson, 2000; Wymer, Riecken, \& Yavas, 1996). Tasks that are perceived as demanding, anguishing, tough, or boring could result in the volunteer leaving the organization. Volunteers' commitment to the organization is also influenced by their relationships with clients, the volunteer coordinator, and paid staff. Volunteers' commitment to an organization increases when they can participate in some of the decision-making processes, receive adequate support and supervision, are not marginalized, and are appreciated by the organization and the clients. Agreement with the organization's ideologies, policies, and practices, and feeling like they are making a concrete difference to the client and to the organization will also influence a volunteer's level of commitment (Behnia \& Bergin, 2001; Caro \& Bass, 1995; Fischer \& Schaffer, 1993; Gill \& Mawby, 1990; Ilsley, 1990; Ng, 1993). Finally, the reactions of significant others may influence a volunteer's commitment to an organization. The disapproval of relatives, friends, and colleagues could negatively influence a volunteer's decision to continue their contribution (Behnia \& Bergin, 2001; Snyder, Omoto, \& Crain, 1999; Wymer, Riecken, \& Yavas, 1996).

Despite the existence of a broad and rich literature on formal volunteering, there is very little knowledge on volunteers who do volunteer work with newcomers to Canada. What motivates them to volunteer with newcomers? What challenges do they face in doing volunteer work with newcomers? Why do some of them continue their work with newcomers while others do not? Answers to these questions will enhance the recruitment and retention capacity of organizations in respect of these volunteers.

\section{METHODOLOGY}

This study, conducted in 2009-2010, adopted a descriptive qualitative exploratory research design. Face-toface interviews with 60 Canadian- and foreign-born volunteers who volunteered with newcomers were conducted in Ottawa. In 2009-2010, participants were recruited from a variety of community organizations that match newcomers with volunteers. To recruit volunteers for the research, the investigator contacted the volunteer coordinators of relevant service agencies and explained in detail the study objectives and method, and the anonymity and confidentiality principles. Interviews with volunteers, lasting approximately 60 minutes each, were conducted at a time and location convenient to them. With the exception of two participants, all 
gave permission to having the interviews audio taped. An interview guide was used to collect the qualitative data. The interview guide contained open-ended questions about volunteers' motivations for working with newcomers, their experiences with newcomers, the organizations, the assigned tasks, and the reasons they continued to volunteer.

After the interviews were completed, the investigator read the transcribed interviews in order to gain a comprehensive understanding of the data as a whole. In the next step of analysis, the investigator re-read each interview transcript carefully to identify emergent patterns, themes, and categories. This step involved indexing data by applying labels to passages or excerpts of transcripts. These labels signified themes, categories, or aspects of experiences addressed by the excerpts. The process of indexing allowed a rereading of data within index categories, synthesizing, and interpreting and finding patterns.

\section{Table 1. Socio-demographic characteristics of the study participants}

\begin{tabular}{|l|r|r|r|}
\hline & $\begin{array}{c}\text { All Volunteers } \\
(N=60)\end{array}$ & $\begin{array}{c}\text { Canadian-born } \\
\text { Volunteers } \\
(N=37)\end{array}$ & $\begin{array}{c}\text { Immigrant } \\
\text { Volunteers } \\
(N=23)\end{array}$ \\
\hline Female & 43 & 26 & 17 \\
Male & 17 & 11 & 6 \\
\hline $16-24$ & 4 & 3 & 1 \\
$25-49$ & 16 & 7 & 9 \\
$50-64$ & 25 & 18 & 7 \\
65 and over & 15 & 9 & 6 \\
\hline Married/Common law & 35 & 19 & 16 \\
Single & 12 & 7 & 5 \\
Widowed & 3 & 2 & 1 \\
Separated/Divorced & 10 & 9 & 1 \\
\hline Some high school & 1 & 0 & 1 \\
Completed high school & 1 & 1 & 0 \\
Some post-secondary school (college & 5 & 2 & 3 \\
or university) & & & \\
College diploma/Certificate & 7 & 6 & 1 \\
University degree & 46 & 28 & 18 \\
\hline Employed full-time & 18 & 10 & 8 \\
Employed part-time & 12 & 6 & 6 \\
Unemployed & 2 & 1 & 1 \\
Student & 3 & 1 & 2 \\
Retired & 20 & 17 & 3 \\
Other (e.g., work at home) & 5 & 2 & 3 \\
\hline
\end{tabular}

\section{SOCIO-DEMOGRAPHIC CHARACTERISTICS}

As Table 1 shows, the majority of study participants were Canadian-born (62\%), female $(72 \%), 50$ years or older $(67 \%)$, married $(58 \%)$, and had a university degree $(77 \%)$. A comparison of the socio-demographic characteristics of the Canadian-born and immigrant volunteers shows similarities in a number of areas. In 
both groups, about $70 \%$ were women and about $75 \%$ had a university degree. The two groups, however, differed in characteristics such as age, marital status, and employment status. Compared to Canadian-born volunteers, a higher percentage of immigrant volunteers were in the $16-49$ age group ( $39 \%$ vs. $19 \%$ ), lived with a partner ( $70 \%$ vs. $51 \%)$, and were in the labour force (61\% vs. $43 \%)$. The proportion of those who were retired was three times higher among Canadian-born volunteers ( $46 \%$ vs. $13 \%$ ).

Canadian- and foreign-born volunteers who participated in this study perceive that they make an invaluable contribution to the lives of newcomers by providing practical, informational, and emotional support. They tangibly helped newcomers to find jobs, learn and practise English, fill out forms and navigate bureaucracies, and conduct everyday activities such as shopping, taking the bus, banking, and money management. Volunteers also offered friendship and support and played an important role in explaining and interpreting Canadian culture. Newcomers often needed information about the cultural values and beliefs that shaped their interaction with Canadians. As one volunteer reported, "So all these [immigrant] women really want to know is how do Canadians do things, what do Canadians think about this, what's acceptable in Canadian culture." The unwritten nature of cultural rules can prevent newcomers from building relationships and accessing resources, which in turn can cause frustration, misunderstanding, and discouragement. Volunteers helped newcomers by lending an ear and clarifying misunderstandings.

When [newcomers] don't understand Canadians, because we are sort of "strange" people, they know they can come to me and bounce questions at me. "Why do you people do like this?" and I can try to explain it to them without them having to be frustrated. (Interview respondent)

Immigrant volunteers gave advice and guidance to newcomers on how to adjust to Canadian society by sharing their personal experiences with them. For example, immigrant volunteers advised newcomers to first focus on learning English/French if they wanted to get a good job, and to be flexible and look for job opportunities in fields other than their own. Some immigrant volunteers helped newcomers to deal with family and intergenerational conflicts and tension.

Volunteers also acted as mediators between newcomers and their private sponsors' ${ }^{1}$. Due to their lack of knowledge of language and culture of the host country, newcomers reported to volunteers that they would often seek the sponsors' guidance for basic everyday life activities such as banking, taking the bus, and shopping. This generated paternalistic behaviour on the part of some sponsors. One volunteer, for instance, reported that there are sponsors who go to newcomers' homes and

look in their cupboards and see what they had bought-umm, juice in cans rather than frozen orange juice-and say that's not economical enough and ... make them go back to the store. (Interview respondent)

Some volunteers, therefore, intervened when they noted that the sponsors were taking over the autonomy and decision making power of newcomers. One immigrant volunteer reported how she had to intervene in order to convince a sponsor who was adamant that the sponsored female refugee had to have her own bank account because that was the "Canadian way" and the "sign of independence."

I said ... [the newcomer] had just come from the atrocious, atrocious time where they have been pushed out of their country, where their brothers and sisters being killed ... and you want them to be independent and have their own bank account? I said "Did they 
ask you?" She said "No, but they have to." ... I said 'If you want them to be Canadians, give them time, give them time to taste the culture'... So she stopped. (Interview respondent)

\section{BECOMING A VOLUNTEER}

Researchers have identified motivation as one of the key factors influencing one's decision to become a volunteer (Fischer \& Schaffer, 1993; Stürmer \& Snyder, 2010; Wymer, Riecken, \& Yavas, 1996). However, the findings in this study reveal the presence of two additional important factors. To become a volunteer one also needs to (1) have a positive attitude toward volunteering behaviour and (2) believe that they possess the skills and abilities necessary for achieving the desired goal. These three factors are presented below.

\section{Motivational reasons}

Most of the study participants volunteered for altruistic reasons such as the desire to help others, to create a fair and just society, to give back to the community, and to ease newcomers' resettlement. However, the responses of some of the study participants indicated the presence of self-oriented motivations such as reducing their own social isolation, obtaining job experiences, and learning about other cultures. Study participants gave more than one reason for engaging in volunteer work. However, for the sake of analysis, their reasons are presented here in separate sub-categories.

\section{Social values}

The primary motive for a number of volunteers reflected their values around a fair and just society. Inequality and injustice made them sad, angry, outraged, and even feel guilty. For instance, in explaining the reasons for her involvement in volunteer work, one study participant stated: "I don't feel happy with things unequal, with people suffering and nobody is helping them." They expected to bring about changes by getting involved in volunteer activities. One study participant, who identified social injustice as her motivation, commented that volunteering:

Makes me feel better because ... there [are] a lot of things that are wrong and a lot of things you can't control, and I find I get depressed if I just think of everything that's out there. So if I zero in on one thing then I feel okay.

The desire to address gender discrimination and inequality was a major motivation mentioned by volunteers. A number of respondents volunteered to teach English to female newcomers because they believed that lack of equal access to an English as a Second Language (ESL) program makes immigrant women socially isolated, dependent on their husbands and children, and relegated to working in low-paying and dead end jobs. They believed teaching language to newcomer women would facilitate their successful integration into Canadian society.

The primary motive of volunteering for a number of Canadian-born participants was their sense of moral obligation due to their position of privilege. They believed that they lived with abundance and comfort and they volunteered in order to share it with others.

We have been incredibly blessed with, with a happy marriage, good kids ... good jobs ... There are people out there that really need, they haven't had that ... and refugees in 
many respects are the people who have had ... the worst of ... around the world. (Interview respondent)

Finally, religious teachings and vision of how a society and human relationships should operate motivated a number of Canadian-born volunteers. One volunteer explained "the biblical injunction to welcome the refugees, the landless, the visitors, the strangers" as the reason for volunteering. Another one explained that, as a Catholic,

I always had believed to whom much is given, much is expected, I do think that you give back, you have to ... Yeah, it's one of my fundamental values.

\section{Facilitation of newcomers' settlement}

A common reason stated by study participants for becoming a volunteer was their desire to facilitate newcomers' transition to Canadian society. Immigrant volunteers referred to their own personal experience of being a newcomer, and facing the challenges of adjusting to a new culture and language, as the reason for volunteering with newcomers. "Because I know that it's very hard when ... you don't know the language, you don't know where to go, you don't know the services, and you're lonely, isolated" (Interview respondent). They could therefore relate to the difficulties experienced by newcomers. "Well, being a newcomer ourselves we know how hard it is" (Interview respondent). Consequently, they decided to volunteer with newcomers in order to ease their adjustment to life in Ottawa.

Although Canadian-born volunteers did not have a direct immigrant experience, witnessing the significant challenges recent immigrants face in a new society led them to volunteering with newcomers.

When I was in university ... there were a lot of international students there. And you could see the difficulty that they would have trying to integrate into Canadian society. So ... [when] I came to Ottawa I could see the same hardships going on ... It's a new country, new language, it is kind of scary. (Interview respondent)

\section{Building new relationships}

For a number of participants, volunteering was a way of meeting others and establishing a relationship. For instance, a Canadian-born volunteer explained

I am keen to have new friends because I have just moved back here to Ottawa, so my friends are all on the other side of Ottawa. So I thought it would be nice to have somebody on this side. And when you teach, you make a friend.

A number of immigrant volunteers also echoed a similar explanation. They spoke about the difficulty of living in a new country without an extended network of friends and relatives. They expected that volunteering would help them to establish new relationships.

I don't have a big family, I cannot live alone ... I would have friends [when I volunteer] ... Even if they are not very close friends, but you know, you have someone to talk to. (Interview respondent) 
The desire to learn about other cultures, countries, and people motivated a number of participants to volunteer with newcomers. For instance, an immigrant volunteer of Latin-American background stated, "I said well you know I already know about what the Latin culture is about, let's learn about other things."

\section{Enhancement of employment opportunities}

Some volunteers interviewed for this study work with newcomers with the intention of improving their own chances of getting a job. Volunteering provided an opportunity for interviewees to practise their interpersonal skills, to gain Canadian work experience, to get letters of reference, and to acquire work-related skills. Sometimes, volunteering allowed study respondents to test out potential new job directions through the experience of working with newcomers and in a teaching environment. One volunteer explained, "I was sort of using [volunteering with newcomers] as a sort of a testing ground for a career path ... [in] the ESL" (Interview respondent).

\section{Representation of Canada and Canadians}

Volunteering with newcomers made a number of Canadian-born volunteers aware of their identity as a Canadian. Some of them were worried about the bad reputation that the treatment of newcomers in Canada could bring upon Canada and Canadians.

Sometimes I am a bit discouraged about what we do [with newcomers] in this country ... I'd like to think that I am giving a message that "No, we gotta keep the doors open ... we have to embrace each other." (Interview respondent)

Conceiving themselves as representatives of Canada and Canadians, these volunteers wanted to "present Canada and Canadians in a good light." Consequently, they saw volunteering as an opportunity to show the goodness of Canadians to newcomers. "I am hoping that I am representing Canadians, that we are good people ... and that we like people, we like diversity" (Interview respondent).

\section{Positive attitudes toward formal volunteering}

The responses of the interviewees indicated the presence of positive attitudes toward volunteering. However, a closer look at the responses reveals that their positive attitudes toward this form of helping behaviour often stemmed from a number of intermediary factors. A number of volunteers, mainly Canadian-born participants, referred to family tradition as a reason for volunteering. Their responses showed the impact that exposure to generosity has on one's behaviour, particularly at a young age. They spoke extensively about growing up in an environment where members of their family and community did volunteer work. Such socialization played an important role in their future engagement in helping behaviours. The tradition of volunteering instilled in them the desire to help others. "I guess it was my family that sort of got me into it ... because my parents always had an interest in helping out newcomers" (Interview respondent).

The accounts of volunteers born into immigrant families showed that their decisions to volunteer with newcomers stemmed from their expectations about the positive outcomes of volunteering. Participants whose parents immigrated to Canada reported that they were aware of the difficulties experienced by their parents when they migrated to Canada and the importance of support they received from the community. The positive outcomes of 
volunteering that they had experienced were tangible evidence of the positive influence that volunteering can have on the lives of newcomers. Thus, they decided to do volunteer work with newcomers.

I think what really helped to make up my mind is my dad [who] came as a child, as an immigrant ... It was the community that really helped him to integrate and so [volunteering with newcomers] was just the right thing to do. There was no question. (Interview respondent)

With respect to immigrants and volunteering, it is important to note that while informal volunteering-i.e., helping others without the assistance of an intermediary organization (IIsley, 1990)-is a universal practice, formal volunteering could represent a new concept for some immigrants. In some countries, volunteer work for an organization is considered as "free labour" or "unpaid work" and therefore as undervalued (Behnia \& Bergin, 2001; Chareka, Nyemah, \& Manguvo, 2010; Couton \& Gaudet, 2008; De Long, 2005; Handy \& Greenspan, 2008; Musick \& Wilson, 2008). An immigrant volunteer, for instance, explaining the absence of formal volunteering in her country of origin stated, "You did not have someone helping you without getting payment. They'd think, excuse me, that you are foolish." Another immigrant participant who reported that members of her community conceived volunteering as "unpaid labour" stated that her friends asked her, "Why do you do things and not get paid?" Consequently, some immigrants may be reluctant to do volunteer work with organizations.

However, exposure to the generosity of volunteers played an important role in engaging immigrants in volunteering. Immigrant volunteers were positively surprised, touched, and impressed with the kindness of volunteers who helped them in their settlement when they arrived in Canada. Consequently, they decided to assist newcomers through volunteering. One study participant, for example, reported that when she received help from a Canadian-born volunteer she told herself, "Okay when I establish my life a little bit, you know, I am gonna do the same." The assistance and help that they received from volunteers when they arrived in Canada was tangible evidence they had of the positive difference that volunteering can make to the lives of newcomers. A number of immigrant volunteers connected their success in adjusting to Canadian society with the help received from volunteers. "My Canadian friends made a difference in my life ... and I know part of my success is to do with their help to me" (Interview respondent). The widespread presence of formal volunteering in Canada also played an important role in generating positive attitudes among immigrants. The very high esteem in which they held volunteering is typified by the following comment.

Here really everybody does [volunteering] and I find it a great thing ... I think it embodies a lot of good Canadian values ... Its generosity, its compassion ... its taking care of others, its sense of community. (Interview respondent)

\section{Perceived self-efficacy}

One of the essential requirements of formal volunteering is the availability of resources such as time, skills, knowledge, and information (Behnia \& Bergin, 2001; Fischer \& Schaffer, 1993). However, the findings of this study reveal the presence of another important resource-the confidence in one's ability to perform the helping behaviour. When study participants were asked the question, "What challenges did you anticipate once you decided to work with newcomers?" immigrant volunteers reported they did not foresee any challenges. This was because they believed their own personal experiences gave them a particular understanding of the difficulties newcomers confront. The presence of a common past gave immigrant volunteers confidence that they could help other newcomers. 
However, when the same question was asked of Canadian-born volunteers, they reported anticipating a number of obstacles such as concern regarding their ability to communicate effectively with newcomers, and to overcome the cultural differences between them.

I was terrified. I remember ... the first time [that] I had to phone her and set up my ... meeting with her and then I thought "oh my god what happens if she doesn't understand me ... what am I going to do?" (Interview respondent)

Nevertheless, they believed that they would be able to overcome challenges of working with newcomers. Their training in mediation, teaching experiences, and years of working in the community, travelling abroad, and being a member of a Francophone minority in Canada gave one respondent enough confidence to start working with newcomers.

Being a French Canadian and having Acadian background, that history of, you know, a group of people that are pushed aside and not treated as equals in the history of Canada, I think, there is a sensitivity to what is different, to not belonging. (Interview respondent)

Confidence in their skills and capacities encouraged Canadian-born individuals to engage in volunteer work with newcomers, despite their concerns.

\section{REMAINING A VOLUNTEER}

Participants' accounts show that the experience of volunteering could challenge or confirm volunteers' expectations and beliefs about their capacity to help as well as the positive results of their helping behaviour. Participants' decision to continue or to discontinue their work with newcomers was influenced by a number of factors. The next two sections will report on the challenges of volunteering with newcomers and then the reasons for continuing volunteer work.

\section{Challenges of volunteering with newcomers}

It is often assumed that volunteers and clients will get along because one has the desire to help and the other needs the help (Gavin, Gavin, Begley, \& Brodie, 2003). However, formal volunteering often brings into contact individuals of different cultural and social backgrounds that can challenge their relationships and interactions. In their volunteer work with newcomers, the study participants faced a wide range of interpersonal challenges such as newcomers' lack of punctuality, reliability, transparency, and knowledge of English. Talking about the frustration caused by lack of reliability one study respondent reported that,

She wasn't reliable, many times I would go to her house and she either wasn't there or she wouldn't answer the door ... The problems continued so I finally ... said I couldn't continue with this.

Lack of transparency was another challenge mentioned by a number of volunteers. They reported experiencing shock and disappointment to discover that the matched refugees did not always tell them the truth about themselves and their past. "Sometimes ... that hurts ... when you come very close to someone and you realize that what I have heard they said was fabrication" (Interview respondent). However, participants were also quick to acknowledge that a lack of transparency can be a survival technique for some refugees. "Sometimes they lie for the reason to get out [of their country] because they are afraid that the 
reason they would give is not good enough" (Interview respondent). This perspective helped them to consider the situation from which newcomers were coming and to continue their relationships with them.

Lack of knowledge of language was mentioned as an additional challenge and sometimes a source of frustration. "You say 'Hi, how are you?' to her and she just looks at you and asks her husband. It is a real source of challenge" (Interview respondent). As participants reported, sometimes the words weren't there, so it became a struggle to communicate. They had to resort to charades and hand gestures.

In a number of cases, the volunteers' uneasiness with newcomers' cultural values was the source of frustration and tension. Reporting about her experience of volunteering with Muslim women, a Canadianborn volunteer respondent stated,

I was [upset] when I discovered my first lady, umm was fully covered whenever she left [home]. ... And my third lady, I was really hoping that she wasn't like that...Well, [she covered herself] in black...and she looked at me and she said ... "are you surprised?" and I said "yes" ... It was depressing for me because that woman and the previous woman, will never, as long as they are wearing that, they will never integrate and be Canadian in the way we think ... I just try not to think about it because it's ... depressing.

The tasks and responsibilities that organizations assign can also be challenging and demanding. Teaching new and unfamiliar subjects and doing translation in stressful circumstances were examples of this type of challenge. "[n hospital] I was like 'oh my god ... what if I say the wrong thing and they give the lady the wrong medicine" (Interview respondent). A number of volunteers talked about the challenge of teaching English to newcomer mothers in their homes.

She had three children under the age of three at home with her. When you are trying to run the class and one of the kids would literally be standing on the table and grabbing stuff ... I had to just focus on her and not get upset by anything. (Interview respondent)

Another challenge identified by participants was organizing activities with newcomers. Sometimes volunteers found themselves short on ideas for joint activities or that the activities suggested by them (e.g., winter outings and sport) were not liked by newcomers.

They have a child and we don't have kids. Sometimes trouble with finding things to do that would also be appropriate for the child ... So I guess that's something that prevents us from doing things [together]. (Interview respondent)

A number of immigrant volunteers reported the negative reactions of their relatives and friends to their volunteer work. Negative reactions were often caused by the novelty of the concept of formal volunteering and the concern for the negative effects that volunteering could have on a volunteer's school performance, family responsibilities, and employment. Finally, participants identified a number of challenges associated with the organizations, transportation (access, travel time), winter weather, fatigue, and the associated costs of volunteering.

\section{Continuing volunteer work}

Despite all the challenges, most of the volunteers interviewed remained committed and only a small number of them reduced their involvement or discontinued their volunteer work. The decision to continue work with 
newcomers was often influenced by various factors including satisfaction with their relationships with newcomers, establishment of new friendships, ability to complete the tasks and activities they were assigned, the positive outcomes of their volunteer work, feeling useful, and being appreciated by newcomers and organizations. Their responses showed that volunteering was not just beneficial for the newcomers; it was equally helpful to the individual who was volunteering.

Seeing the positive effects of their volunteer work was a major reason to continue their volunteer work with newcomers. A number of volunteers relayed their happiness on watching the progress newcomers made in their transition to Canadian society. Newcomers' progress was a confirmation of their contributions.

I think if I didn't see progress then I might get a little umm, maybe a little bit disappointed not in my students but in myself, that I wasn't able to get her to a level that was helpful for her. (Interview respondent)

Respondents explained the sense of joy and fulfilment they experienced when they felt that what they were doing was helping others. They continued because they felt helpful and useful.

I remember first time [that] ... I was able to help her and to see that pleasure in her face...I felt totally needed and I felt like I was actually accomplishing something ... It is nice to feel useful. (Interview respondent)

The need to see the positive effects of their helping behaviour was so important for volunteers that some newcomers' lack of feedback made some volunteers uncertain about their contribution. "The fact that l'm not getting feedback from them, l'm not sure how to interpret [that] ... Do I actually know what my success rate is?" (Interview respondent). Consequently, the newcomers' expression of satisfaction made volunteers happy and reassured them about their contribution.

When I see the joy in his face, it makes me happy. But sometimes you have somebody, nothing is said, no expression is said. So then you have this feeling of confusion of "Did I really help him or not?" With him, every night I feel like I did help him because he is always happy. (Interview respondent)

No wonder, then, that some volunteers reported that they preferred long-term relationships with newcomers. It allowed them to see the outcomes of their actions.

I would like to pursue .... the same person so that I can see the outcome and the differences that I have made ... If I meet this gentleman five years later, I won't know that I helped him to get to that point. It might have been somebody else ... it is not the outcome of my work. (Interview respondent)

The appreciation shown by newcomers and organizations was another important factor encouraging volunteers to continue their work. This appreciation generated an enormous amount of personal satisfaction among volunteers. Appreciation and gratitude shown by newcomers and organizations was an indicator of their positive contribution to newcomers, and it made them "feel wonderful" and even boosted their sense of confidence. 
I think it's given me more confidence too. Because these women are very appreciative ... and it's nice to be appreciated, because you don't always get that from your job and your family (laughter). (Interview respondent)

Another positive outcome of volunteering was the development of friendships. Volunteering not only allowed volunteers and newcomers to get to know each other but also to develop friendships. "You get another person who really cares about you" (Interview respondent). Volunteers extensively talked about the care and affection that they received from newcomers. Some newcomers helped volunteers in moving to a new house or comfort them during difficult times.

When my husband was ill ... I couldn't believe the outpouring and the support and the way we were just held ... by some who had never met him. Because I knew them through volunteering. (Interview respondent)

Some volunteers, therefore, considered newcomers as part of their support systems. "I feel that I have a ... group in the city that, if I asked for help, would be there" (Interview respondent). The way that some of the study participants talked about the newcomers show the presence of a deep level of connection and attachment between them. They talked about newcomers and their families with such affection, joy, and pride as if they were talking about their own family members. Many volunteer relationships with newcomers continued after the designated period of the match and they remained in touch.

They have gone back to their home country and we stayed in contact. So now I can go to Korea, I can go to Iran ... and stay with them, which is fantastic. (Interview respondent)

Talking about the benefits that they got from volunteering with newcomers, study participants emphasized that they learned a lot about the world, diversity, and other cultures. "I have never been out of the country ... So it has really opened my eyes to what people have experienced outside of Canada" (Interview respondent). They also gained a broader understanding of people's different experiences, and gained a different perspective on world affairs.

You can hear about the fighting in Darfur, or ... the problems in South Kiboo, and in the Democratic Republic of Congo ... But when you actually meet people ... you realize the personification of that problem. (Interview respondent)

Another identified benefit of volunteering with newcomers was that it pushed volunteers beyond their comfort zones as well as shattered some of the existing misconceptions and stereotypes that they held toward newcomers and other cultures. Volunteering with newcomers also increased their ability to listen and be more patient.

It has made me more patient just in general with people because you never know people's stories. So it's actually nice to interact with people with such different backgrounds and be aware that ... everybody is different. (Interview respondent)

The opportunity to work and to feel useful was mentioned by a number of immigrant volunteers as the reason to continue their volunteer work. 
[Volunteering] makes you feel alive. When you stay home ... you feel you are just wasting your life ... I felt frustrated, no job, no life, nothing. Now ... I feel like working ... That makes me feel useful. So, I don't take myself, you know, being jobless. (Interview respondent)

\section{DISCUSSION}

To successfully recruit volunteers and to ensure that those who are recruited remain committed to formal volunteering, it is important to identify factors that encourage and hinder their collaboration with newcomers. By examining the experience and perspectives of Canadian- and foreign-born volunteers, this study aimed to identify factors that lead individuals to initiate and continue to volunteer with newcomers. While the findings of this qualitative study have corroborated some of the empirical knowledge that exists in the general field of volunteering, this study has contributed new information to the body of knowledge of volunteering by shedding some light on volunteering with newcomers.

Consistent with the findings of other studies on volunteering, altruistic and self-interested reasons played an important role in motivating study participants to volunteer with newcomers (Behnia, 2007; Clary \& Snyder, 1991; Dekker \& Halman, 2003; Fischer \& Schaffer, 1993; Green \& Chalip, 2004; Musick \& Wilson, 2008; Snyder \& Omoto, 1992; Stürmer \& Snyder, 2010; Wilson, 2000). The study participants' accounts of their motivations reveals the presence of similarities and differences between Canadian- and foreign-born volunteers. Both Canadian- and foreign-born volunteers in this study volunteered in order to facilitate newcomers' settlement, address social inequality and injustice experienced by immigrants, build new relationships, reduce their social isolation, learn about other cultures, and improve their employment opportunity. However, it was only Canadian-born volunteers who reported their own sense of abundance, religious teachings, and the desire to project a positive image of Canada and Canadians as reasons for volunteering.

\section{Practice implications}

The results of this study provide some insight into factors that motivate Canadian- and foreign-born individuals to volunteer with newcomers, as well as into the challenges of volunteer work with newcomers. The study findings can inform organizations how to promote volunteering with newcomers, to enhance their recruitment capacity, and to succeed in retaining volunteers.

In their promotional activities, organizations need to

1) advertise the positive impact of volunteer work on newcomers and volunteers themselves, and the rewarding nature of volunteer work with newcomers;

2) explain why volunteers are needed, what they will be doing, and what type of skills are needed, as well as time requirements;

3) advertise the training and workshops they offer on cross-cultural communication and mediation, and information sessions on the culture and countries with which volunteers will be matched; and

4) invite volunteers and previously matched newcomers to community meetings, ethno-cultural events, and orientation sessions to talk about their experiences and what differences volunteers make to the lives of newcomers. 
Once volunteers commence their volunteer work, organizations must provide them with adequate training programs, ongoing support, and follow-up. These activities keep volunteers and organizations connected and help organizations retain volunteers.

Organizations are advised to

1) take into consideration volunteers' motivations, interests, comfort, and preferences when assigning tasks to them;

2) offer training to raise volunteers' knowledge of world events, characteristics of different cultures, cultural biases and stereotypes and their effects on relationships with newcomers, and of how to deal with cultural and linguistic differences;

3) maintain regular contact with volunteers through one-on-one meetings, telephone calls, emails, and/or correspondence. The aim of the follow-up is to check in on how things are going, to discuss issues occurring in the matches, and to monitor volunteers' activities in order to see whether their intervention is necessary;

4) explain to newcomers about program expectations such as regulations concerning cancellation, missing appointments, and participation in organizing joint activities;

5) appreciate volunteers by publishing articles in local and ethnic media and newsletters, handing out volunteer certificates, holding special group events in recognition of volunteers, and giving them letters of reference; and

6) inform volunteers about newcomers' appreciation and acknowledgement of their contributions.

\section{CONCLUSION}

This study has contributed to the knowledge on volunteering by revealing the presence of two other important factors in addition to motivation for volunteering. To become a volunteer, one not only needs to be motivated but also needs to believe that volunteering will produce the expected positive results and to have confidence in one's ability to complete the tasks required to achieve the desired goals. While Canadian-born volunteers revealed that a positive attitude toward formal volunteering was mainly a product of growing up in a family and community with the tradition of formal volunteer work, for immigrant volunteers a positive attitude toward volunteering was learned by witnessing its positive effects on their own or other immigrants' lives. With respect to self-efficacy, Canadian- and foreign-born volunteers differed on the sources of their sense of confidence. While Canadian-born volunteers mentioned skills learned through work and training, foreign-born volunteers drew on their experience of being an immigrant.

One of the major challenges faced by community organizations is the retention of volunteers. Although there are no statistics available on the number of volunteers who discontinue their volunteer work, there are numerous accounts that show attrition among volunteers as a persistent challenge for organizations. Researchers have reported that retention of volunteers is sometimes more difficult than their recruitment (Behnia, 2007; Fischer \& Schaffer, 1993; Green \& Chalip, 2004; Penner, 2002; Snyder \& Omoto, 1992; Wharton, 1991). As noted above, research on volunteering indicates the importance of satisfaction with the assigned tasks, the organization itself, and relationship with clients served in the decision to continue his/her volunteer work with an organization. In this regard, the results of this study confirmed the findings of previous studies (Behnia \& Bergin, 2001; Caro \& Bass, 1995; Fischer \& Schaffer, 1993; Gill \& Mawby, 1990; Ilsley, 1990; $\mathrm{Ng}, 1993)$. 
This study revealed that once one becomes a volunteer, the experience of volunteering tested their belief about their self-efficacy and the positive outcomes of their volunteer work. Success or failure of their own expectations could influence their decision to continue or discontinue their volunteer work. The study results also revealed that volunteers wanted to know whether they were making a difference in the newcomers' lives. Therefore, volunteers considered the progress in newcomers' ability to navigate Canadian society, development of friendships with newcomers, learning about other cultures, and newcomers' and organizations' appreciation of their contributions, to be signs of achievement.

\section{ACKNOWLEDGEMENTS}

I would like to thank my colleague Dr. Patricia Evans for her careful reading of an early version of this article and providing me with invaluable suggestions. This research project was funded by the Citizenship and Immigration Canada - Ontario Region.

\section{NOTE}

1. The Private Sponsorship of Refugees Program allows groups to sponsor refugees from abroad who qualify to come to Canada. Groups of five or more Canadian citizens or permanent residents, or groups of religious organizations, ethno-cultural groups, and humanitarian organizations can assume responsibility to provide financial, practical and emotional support for the refugees for the duration of the sponsorship. This includes helps with housing, food, clothing, and learning how to navigate the system.

\section{REFERENCES / BIBLIOGRAPHIE}

Ashton, S., Baker, N., \& Parandeh, A. (2006). Building caring communities: The contributions of immigrant volunteers. Coquitlam, BC: Community Volunteer Connections.

Basran, G.S., \& Zong, L. (1998). Devaluation of foreign credentials as perceived by visible minority professional immigrants. Canadian Ethnic Studies, 30(3), 6-23.

Bauder, H. (2003). "Brain abuse", or the devaluation of immigrant labour in Canada. Anipode, 35(4), 699-717.

Behnia, B. (2007). An exploratory study of befriending programs with refugees: The perspective of volunteer organizations. Journal of Immigrant and Refugee Studies, 5(3), 1-19.

Behnia, B. (2004). Refugees' convoy of social support. Community peer groups and mental health services. International Journal of Mental Health, 32(4), 6-19.

Behnia, B., \& Bergin, B. (2001). Ethnocultural communities and formal volunteering: An exploratory study. The Journal of Volunteer Administration, 19(3), 2-14.

Beiser, M. (1999). Strangers at the gate. The 'boat people's' first ten years in Canada. Toronto ON: University of Toronto Press.

Canadian Centre for Victims of Torture. (n.d.). CCVT volunteer handbook. Toronto, ON: Canadian Centre for Victims of Torture.

Caro, F.G., \& Bass, S.A. (1995). Increasing volunteering among older people. In S. Bass (Ed.), Older and active. How Americans over 55 are contributing to society, (pp.71-96). New Haven, CT: Yale University Press.

Charbonneau, J., \& Laaroussi, M.V. (2003). Twinning projects between immigrant families and Quebecois families: Volunteer work, mutual aid, or intervention? Journal of International Migration and Integration, $4(4), 453-470$.

Chareka, O., Nyemah, J., \& Manguvo, A. (2010). Conceptions of volunteerism among recent African immigrants in Canada: Implications for democratic citizenship education. Canadian Social Studies, 43(1), 3-20. 
Citizenship and Immigration Canada. (2004). Evaluation of host program. Ottawa, ON: Citizenship and Immigration Canada.

Clary, E.G., \& Snyder, M. (1991). A functional analysis of altruism and prosocial behavior: The case of volunteerism. In M.S. Clark (Ed.), Prosocial Behavior, (pp. 119-148). London, UK: Sage Publications.

Couton, P., \& Gaudet, S. (2008). Rethinking social participation: The case of immigrants in Canada. Journal of International Migration and Integration, 9(1): 21-44.

Creese, G., \& Kambere, E. N. (2003). What colour is your English? The Canadian Review of Sociology and Anthropology, 40(5), 565-573.

Dekker, P., \& Halman, L. (2003). Volunteering and values: An introduction. In P. Dekker and L. Halman (Eds.), The values of volunteering. Cross-cultural perspectives, (pp. 1-17). New York, NY: Kluwer Academic/Plenum Publishers.

De Long, B. (2005). The meaning of volunteering. Examining the meaning of volunteering to new Canadians. London, ON: Pillar-Voluntary Sector Network.

Employment and Immigration Canada. (1986). First report on the host program: Pilot projects in London, Winnipeg and Regina. Ottawa, ON: Employment and Immigration Canada.

Fischer, L.R., \& Schaffer, K.B. (1993). Older volunteers: A guide to research and practice. London, UK: Sage Publications.

Fletcher, F., \& Fast, J. (2009). Supporting immigrant volunteerism in Canada. A collaborative research project. Australian Journal of Volunteerism, 13, 1-11.

Gavin, J.A., Gavin, N., Begley, S., \& Brodie, D. (2003). Assisting friendship, combating loneliness: Users' views on a 'befriending' scheme. Ageing and Society, 23, 349-362.

Gill, M.L., \& Mawby, R.I. (1990). Volunteers in the criminal justice system. A comparative study of probation, police and victim support. Philadelphia, IL: Open University Press.

Green, C.B., \& Chalip, L. (2004). Paths to volunteer commitment: Lessons from the Sydney Olympic games. In R. A. Stebbins \& M. Graham (Eds.), Volunteering as leisure/leisure as volunteering. An international assessment, (pp. 49-68). Cambridge, MA: CABI Publishing.

Handy, F., \& Greenspan, I. (2008). Immigrant volunteering. A stepping stone to integration? Nonprofit and Voluntary Sector Quarterly, 20(10), 1-27.

Ilsley, P.J. (1990). Enhancing the volunteer experience: New insights on strengthening volunteer participation, learning and commitment. San Francisco, CA: Josey-Bass Publishers.

Kearney, J. (2001). The values and basic principles of volunteering: Complacency or caution? Voluntary Action, 3(3), 63-86.

Lamba, N.K., \& Harvey, K. (2003). Social capital and refugee resettlement: The social networks of refugees in Canada. Journal of International Migration and Integration, 4(3), 335-360.

Lanphier, M., \& Lukomskyj, O. (1994). Settlement policy in Australia and Canada. In H.Adelman, A. Borowski, M. Burstein, \& L. Foster. (Eds.), Immigration and refugee policy. Australia and Canada compared (pp. 337-371). Toronto, ON: University of Toronto Press.

Lanphier, C.M. (1993). Host groups: Public meets private. In V. Robinson (Ed.), International refugee crisis. British and Canadian responses, (pp. 255-272). London, UK: The Macmillan Press Ltd.

Musick, M.A. \& Wilson, J. (2008). Volunteers. A social profile. Bloomington, IN and Indianapolis, IN: Indiana University Press.

$\mathrm{Ng}$, K.K.Y. (1993). Volunteer work and settlement: A study of Chinese immigrant women. Canadian Journal of Community Mental Health, 12(2), 31-44.

Pearce, J.L. (1993). Volunteers: The organizational behavior of unpaid workers. London, UK: Routledge.

Penner, L.A. (2002). Dispositional and organizational influences on sustained volunteerism: An interactionist perspective. Journal of Social Issues, 58(3), 447-467. 
Raj, A., \& Silverman, J. (2002). Violence against immigrant women. The role of culture, context, and legal immigrant status on intimate partner violence. Violence Against Women, 8(3), 367-398.

Reitz, J.G. (2005). Tapping immigrants' skills. New directions for Canadian immigration policy in the knowledge economy. Choices, 11(1), 1-18.

Snyder, M., Omoto, A.M., \& Crain, A. L. (1999). Punished for their good deeds. Stigmatization of AIDS volunteers. American Behavioral Scientist, 42(7), 1175-1192.

Snyder, M., \& Omoto, A.M. (1992). Who helps and why? The psychology of AIDs volunteerism. In S. Spacapan and S. Oskamp (Eds.), Helping and being helped. Naturalistic studies, (pp. 213-239). London, UK: Sage publications.

Stürmer, S., \& Snyder, M. (2010). The psychosocial study of group processes and intergroup relations in prosocial behavior: Past, present, future. In S. Stürmer \& M. Snyder (Eds.), The psychology of prosocial behavior, (pp. 3-12). Chichester, UK: John Wiley \& Sons.

Thompson, J. (1988). Host program for refugee settlement pilot projects. Summary report. Ottawa, ON: Employment and Immigration Canada.

Vallee, M., \& Caputo, T. (2010). Synthesis paper on newcomers and volunteering. Ottawa, ON: Human Resources and Skills Development Canada (HRSDC).

Wharton, C.S. (1991). Why can't we be friends? Expectations versus experiences in the volunteer role. Journal of Contemporary Ethnography, 20(1), 79-106.

Wilson, J. (2000) Volunteering. Annual Review of Sociology, 26, 215-240.

Wymer, W., Riecken, G., \& Yavas, U. (1996). Determinants of volunteerism: A cross-disciplinary review and research agenda. Journal of Nonprofit and Public Sector Marketing, 4(4), 3-26.

Yan, M.C., \& Lauer, S. (2008). Social capital and ethno-Cultural diverse immigrants: A Canadian study on settlement house and social integration. Journal of Ethnic \& Cultural Diversity in Social Work, 17(3), 229-249.

\section{ABOUT THE AUTHOR / L ' AUTEUR}

Behnam Behnia is Associate Professor in the School of Social Work, Carleton University. Email: behnam_behnia@carleton.ca . 